\title{
ALTRUÍSMO E EGOÍSMO NA ECONOMIA E EM OUTRAS CIÊNCIAS SOCIAIS: EXPERIMENTOS E EVIDÊNCIAS EMPÍRICAS ${ }^{*}$
}

\author{
Marco Novarese ${ }^{1}$
}

\section{INTRODUÇÃO}

Este trabalho tem como objetivo analisar os fatores que possam estar na base de comportamentos altruístas empiricamente observáveis e que possam desmentir as tradicionais hipóteses econômicas. Este tema apresenta-se de notável relevância para a disciplina, como pode ser vislumbrado pelos diversos âmbitos de potencial aplicação e pelo elevado número de trabalhos dedicados ao mesmo. Destacamos aqui principalmente os trabalhos da economia experimental, que desde o princípio confrontavam a validade da hipótese do comportamento egoísta. ${ }^{2}$

A análise desta temática requer, sobretudo, que se defina o termo altruísmo. Aqui adotar-se-á um significado amplo capaz de compreender todos aqueles comportamentos que são, ao menos aparentemente, favoráveis a outros e potencialmente desvantojosos para quem os realiza. Esta deste artigo.

* Gostaríamos de agradecer ao prof. Huáscar Pessali pela tradução

${ }^{1}$ Centre for Cognitive Economics - Dipartimento di Scienze Giuridiche ed Economiche - Università del Piemonte Orientale. Facoltá di Giurisprudenza - Corso Borsalino 44. e-mail: novarese@jp.unipmn.it

${ }^{2}$ Recordamos as experiências de Dresher e Flood nos anos 1950, sendo as primeiras de que se tem conhecimento a testar empiricamente a teoria dos jogos (cf. FLOOD, 1952, 1958). Lá se percebeu que nas situações repetidas do tipo dilema do prisioneiro emergia uma tendência à cooperação, embora não perfeita (LEDYARD, 1995), traz uma análise dos resultados. Outros trabalhos se seguiram com objetivos e resultados, ao menos em parte, análogos. Não só a economia experimental, porém, questiona a validade de comportamentos puramente egoístas. Andreoni (1995), Croson (1996), Rabin (1993) e Hudson; Jones (1994), dentre outros mostram exemplos reais, saídos do dia-dia, que desqualificam a hipótese de egoísmo. 
definição compreende por isso a privateness (SEN, 1985, p. 347) suportada pela teoria econômica tradicional e pela teoria dos jogos, onde o bem-estar de um indivíduo está ligado exclusivamente ao próprio consumo e não prevê simpatia ou antipatia pelos outros (self-centered welfare).

Cada indivíduo intervém com o objetivo de maximizar o seu próprio bem-estar (ou o seu valor esperado), não se importando com os interesses dos outros (self-welfare goal). As escolhas feitas visam exclusivamente o prosseguimento dos próprios objetivos sem estarem vinculadas ao reconhecimento dos fins perseguidos pelas outras pessoas (self-goal choice).

A alusão à definição de Sen traz-nos comportamentos altruístas que na literatura são, às vezes, tratados por outros termos - como por exemplo gentileza (kindness), cooperação e adesão a preferências sociais. É possível fazer referência a alguns exemplos:

- A teoria dos jogos prevê que um agente racional envolvido numa situação do tipo "dilema do prisioneiro" escolherá desertar. Em desacordo com esta hipótese estão Bergstrom e Stark (1993) que definem altruísta a escolha de cooperar;

- Uma definição relacionada com a precedente é implicitamente utilizada também nas experiências descritas por Andreoni e Miller (1993), Rabin (1993) e Andreoni (1995) nas quais o termo kindness indica a atitude dos sujeitos que contribuem ao financiamento de um bem público;

- Como observamos, o indivíduo econômico tradicionalmente considerado visa maximizar a própria função de utilidade, que geralmente está ligada exclusivamente ao consumo pessoal. Becker (1976) define como altruísta um indivíduo cuja função de utilidade inclui o consumo dos outros;

- Em situação de assimetria de informação, tendo como base a teoria econômica tradicional, podem surgir problemas de oportunismo, como por exemplo o moral hazard (cf. neste ponto ARROW, 1962, 1986, e PAULY, 1968). Uma das situações em que se verifica este risco é na relação entre empresa e empregados. Uma parte relevante da literatura econômica relativa à empresa ocupou-se somente de analisar as melhores formas contratuais para incentivar os trabalhadores a cumprir o próprio dever contratual. Existem, no entanto, trabalhos que evidenciam como, pelo menos em algumas situações, a relação entre empresa e trabalhador possa ser baseada em lealdade e colaboração (cf. AKERLOF, 1984; SIMON, 1933; EGIDI, 1995 e wITT, 1998). As motivações que estão na base dos vários comportamentos podem ser, como linha de princípio, diversas.

Kahneman, Knetsch e Thaler (1986, p. 102) observam como na literatura econômica a hipótese padrão de altruísmo pode assumir formas 
diferentes (cf. também FEHR; GACTHER, 2000, p. 159). Em alguns casos trata-se de uma hipótese do tipo as if com natureza predominantemente metodológica. No extremo oposto há a posição que nega a possibilidade de qualquer tipo de comportamento altruístico. Aqueles que sustentam esta idéia dificilmente vêem os comportamentos altruístas observados na realidade, atribuindolhes pouca relevância.

Este trabalho estará centrado em uma pergunta principal: como será possível explicar as causas dos comportamentos aparentemente altruístas observados na realidade e nas experiências? É possível dar várias respostas a esta pergunta. As respostas permitirão também ulteriormente esclarecer os possíveis significados e as implicações do próprio conceito em estudo.

\section{ALTRUÍSMO COMO PROCESSO DE OTIMIZAÇÃO OU EGOÍSMO DISFARÇADO}

Uma primeira resposta pode ser baseada nos valores imbuídos na abordagem neoclássica tradicional.

O modelo-base proposto por Becker (1976) prevê dois indivíduos, um egoísta e um altruísta. Na função de utilidade do indivíduo altruísta estão incluídos tanto o seu próprio consumo como o consumo do parceiro. (No que diz respeito a uma situação em que ambos os agentes sejam egoístas, as escolhas de consumo e de produção de bens dos sujeitos são alteradas.) $\mathrm{O}$ altruísta pode escolher transferir uma parte da própria riqueza a outro. A transferência dos recursos continua até que a utilidade marginal do consumo do indivíduo altruísta esteja igual à utilidade marginal do parceiro. Além disso, na fase de produção dos bens, ele abster-se-á de realizar aquelas ações que incrementam o seu rendimento perante uma maior redução do rendimento do indivíduo egoísta. A inter-relação que se cria tem uma consequência importante. O egoísta é, por sua vez, levado a ter em consideração a riqueza global produzida. Evitará, por isso, prejudicar outro indivíduo se tal dano se refletir sobre o que recebe. A análise pode ser ampliada com a introdução de um maior número de agentes. Os resultados permanecem invariáveis. ${ }^{3}$

${ }^{3}$ Conclusões semelhantes sobre a utilidade do altruísmo são encontradas em Rotemberg (1994). Este propõe um modelo em que os indivíduos escolhem racionalmente o nível de altruísmo. Escolhem, isto é, fazem depender a sua utilidade também da dos outros, construindo-se assim uma segunda função de utilidade. A escolha de maximizar a nova função é racional enquanto consente atingir níveis de utilidade de outra forma não 
Becker propõe também uma extensão do modelo-base para analisar o caso em que a utilidade dos agentes dependa, em lugar do consumo, do fitness genético (isto é, da probabilidade de reproduzir-se). Também neste caso o altruísmo pode revelar-se mais eficiente que o egoísmo puro - sempre a causa do comportamento que induz nos outros - e pode por isso resultar vencedor num processo de seleção natural.

Chegam também a conclusões análogas Bergstrone e Stark (1993). No seu modelo, a estratégia de um indivíduo pode ser determinada por fatores genéticos ou pela imitação dos vizinhos. Os autores mostram como pode ser racional escolher comportamentos altruístas também por agentes egoístas interessados em obter o pay-off mais alto possível (que no modelo em análise garante-lhes uma maior probabilidade de se reproduzir). ${ }^{4}$

O altruísmo parece, por isso, integrar-se plenamente à modelização standard, que cessa também o racionalizar.

Posta em destaque por vários autores, a abordagem baseada na função de utilidade tem efeitos neutros em relação aos fins (os objetivos de maximizar). É, por isso, perfeitamente possível introduzir a hipótese de altruísmo, o qual, aliás, em determinadas situações, pode ser interpretado como meio para atingir resultados ótimos e não só como um fim.

A introdução do consumo ou do bem-estar dos outros na própria função de utilidade cria, no entanto, alguns problemas. Por um lado, exprime todos os comportamentos como egoístas, eliminando a possibilidade de se definir qualquer que seja o comportamento altruísta. A noção do egoísmo torna-se tautológica ao integrar qualquer que seja o comportamento (SACCO; ZAMAGNI, 1994). Do ponto de vista cognitivo, ficam apenas por explicar em que cirscunstâncias se deve supor que os agentes sejam altruístas e quando, pelo contrário, sejam egoístas, ou então que hipóteses devam prevalecer. Na modelagem é então necessário recorrer a hipóteses externas. Além dos problemas expostos, outros mais são mencionados por autores que vêem aplicabilidade limitada a situações muito particulares da introdução do altruísmo num esquema econômico padrão (cf. SACCO; ZAMAGNI, 1994; WITT, 1985).

Outros trabalhos, sobre os quais nos debruçaremos nas páginas seguintes, mostram como determinadas formas de altruísmo, numa perspectiva pelo menos em parte diferente e mais ampla do que aquela até agora

atingíveis. Tal resultado depende novamente dos efeitos indiretos sobre o comportamento dos outros (cf. HAMMOND, 1987).

${ }^{4}$ A probabilidade de se reproduzir depende do valor absoluto do pay-off e não da quota individual do pay-off total. 
vista, possam, no entanto, representar comportamentos vencedores e úteis também em contextos mais amplos do que aqueles vistos e com hipóteses e formas de modelagem diferentes. Como veremos, o sentido do termo altruísmo vem ainda a ser inevitalvelmente atenuado em respeito ao significado comum de "amar o próximo."

\section{ALTRUÍSMO COMO RESULTADO DE PROCESSOS DE INTERAÇÃO: "TIT FOR TAT" E SIMULAÇÕES}

Um dos principais e mais notáveis trabalhos sobre o assunto em análise é seguramente o livro The Evolution of Cooperation de Robert Axelrod, publicado em 1984. Como é sabido, Axelrod, a convite de uma série de estudiosos, apresentou variações para um torneio baseado em séries de interações do dilema do prisioneiro.

Foram apresentadas e postas em confronto, utilizando simulações no computador, diversas estratégias. À população era por isso atribuída uma série grandíssima de variações.

Nas sessões, a frequência relativa de todas as estratégias na população era determinada pelos pay-offs mais elevados, isto é, difundiam-se. A estratégia vencedora resultou ser exatamente aquela do tit for tat: colabora se o teu adversário colaborou no turno precedente e, de outra maneira, não colabora. Por isso, um comportamento colaborativo revela-se mais eficiente que o egoísmo puro. ${ }^{5}$

A validade deste modelo não é geral. ${ }^{6}$ Sua importância, porém, se deve provavelmente ao fato da estratégia imaginada ser utilizada para repre-

${ }^{5}$ A existência de soluções óptimas análogas ao tit for tat é demonstrável também analiticamente (folk theorem). O número de repetições do jogo deve ser incógnito aos jogadores, que apesar disso não devem estar demasiado impacientes em "expiar" o futuro. Veja-se o exemplo de Kreps (1993, p. 591).

${ }^{6}$ Young e Foster (1991) qualificam os resultados de Axelrod. Eles mostram que pequenas mudanças nas condições da base do modelo fazem da estratégia tit for tat perdedora no confronto com uma estratégia de defecção pura. Eles confrontam três estratégias (cooperação, defecção, tit for tat) num sistema não determinístico em que o número de interações é uma variável casual. De tal forma os pay-offs, estando ligados ao número de interações, são variáveis. Uma outra hipótese introduzida é a de não extinção de estratégias. Tal hipótese é considerada mais realista, já que as migrações ou a casualidade genética fazem com que nenhuma estratégia se extinga por completo. Outro aspecto considerado é o tamanho de população que interage (mantida estável). Tal número é relevante já que a estratégia tit for tat se revela vencedora só com percentagens não muito elevadas de indivíduos que defecionam sempre. 
sentar, em diferentes contextos, formas de aprendizagem individuais ou coletivas, de nível cultural ou genético. ${ }^{7} \mathrm{E}$, além disso, a estratégia permite resolver o paradoxo social que emerge do dilema do prisioneiro.

A regra do tit for tat poderia, apesar disso, ser utilizada para sintetizar resultados de muitos trabalhos que analisam a teoria em estudo. Trata-se de fato de uma estratégia em que o altruísmo é vantajoso para quem o faz, mas com a condição de que o outro indivíduo se comporte do mesmo modo (isto é, deve haver uma reciprocidade de tratamento). Vários trabalhos conduzem a resultados deste tipo. Veja-se, por exemplo, que nos modelos de Becker (1976) e Bergstrom e Stark (1993) o altruísmo se revela eficiente porque, e só na medida em que, solicita um comportamento similar da parte dos outros. ${ }^{8}$

Skyrms (1996) utiliza uma série de simulações para analisar como diferentes comportamentos altruístas podem difundir-se em nível social. Também neste caso se parte de um simples jogo, uma versão simplificada do ultimatum game em que dois indivíduos devem acordar sobre a divisão de uma torta. Há no ultimatum game dois jogadores, um em posição ativa e um em posição passiva. $\mathrm{O}$ jogador ativo propõe uma divisão num certo número entre ele e o parceiro. Se este aceita a divisão proposta, os dois obtêm a quota acertada. Se o jogador passivo recusa, ninguém obtém alguma coisa. $\mathrm{Na}$ base da estratégia racional, o jogador ativo deveria oferecer o número mais baixo possível ao parceiro que deveria aceitá-la, por quanto um número positivo é melhor que nada. Em certas condições, porém, estratégias altruístas podem resultar vencedoras e difundir-se em nível social. Uma interessante extensão do modelo baseia-se na hipótese de que as uniões entre os jogadores não sejam casuais mas determinadas por algum "mecanismo de co-relação." Indivíduos que usam a mesma estratégia tendem a jogar entre eles mais vezes em relação àqueles que usam estratégias diferentes. ${ }^{9} \mathrm{~A}$ coo-

${ }^{7}$ A teoria dos jogos é também muito utilizada pelos biólogos; veja-se o exemplo de Seltem, 1991. Também Cosmides e Tooby (1992) utilizam este instrumento para formalizar seus resultados. O mesmo Axelrod trabalhou também com Hamilton (cf. AXELROD e HAMILTON, 1981).

${ }^{8}$ Veja ainda Boone (1999). A reciprocidade está também na base de um comportamento honesto analisado por Fehr e Gachter (2000) e Rabin (1993).

${ }^{9} \mathrm{O}$ mecanismo de co-relação que tende a fazer jogar indivíduos que adotam estratégias análogas é, em certos aspectos, comparável à estratégia do tit for tat (ser altruísta só para quem o é na sua vez) e é similar ao mecanismo de seleção dos parceiros proposto por Tullock (1985). Festa (1999) mostra como são fortes as analogias entre as simulações de Skyrms e algumas idéias Hayekianas relativas à evolução espontânea de normas culturais. 
peração é por isso interpretável como resultado de processos dinâmicos que levam a definir normas sociais e por isso pode ser entendida como ordem espontânea não planejada (BICCHIERI, JEFREY, SKYRMS, 1997; BICCHIERI, 1990). ${ }^{10}$

Os modelos mencionados são, por um lado, relacionáveis a vários trabalhos que evidenciam a relevância dos processos de aprendizado (individuais ou coletivos) e o desenvolvimento de normas sociais. Por outro, encontram também um importante sustento (e um campo de aplicação) em vários trabalhos empíricos propostos por biólogos e sociólogos.

\section{ALTRUÍSMO COMO PRODUTO DE PROCESSOS DE EVOLUÇÃO BIOLÓGICA}

$\mathrm{Na}$ base da sociobiologia (WILSON, 1975) está a idéia de que as preferências dos indivíduos não sejam arbitrárias, mas sejam produto dos processos evolutivos. Também a tendência para a cooperação poderia ser o resultado de tais mecanismos, e por isso seria hoje identificada como da própria natureza humana. Para se justificar esta idéia é, no entanto, necessário explicar as vantagens, por uma ótica de seleção natural, dos comportamentos altruístas observados no mundo animal. ${ }^{11}$

Uma primeira explicação faz referência à idéia de group selection. As mudanças evolutivas seriam determinadas por diferentes taxas de extinção dos grupos, mais que dos indivíduos. Os grupos com indivíduos altruístas teriam maior capacidade de sobrevivência e por isso cresceriam à desvantagem dos grupos formados por egoístas. Esta explicação foi sujeita a pesadas críticas e está, hoje, relegada. De fato, a seleção biológica de grupos é pensada impossível pela maioria dos estudiosos, posto que a unidade reprodutiva é o indivíduo (o discurso muda, porém, é considerada a seleção natural, como ilustrou Hayek, 1967, sobre o que voltaremos a falar). ${ }^{12}$

Uma outra explicação está fundada na idéia de kin selection. O indivíduo altruista estaria relacionado exclusivamente com os próprios parentes. O sacrifício de um indivíduo permitiria aos genes presentes na família

${ }^{10}$ Nestes modelos a cooperação é compreendida e desenvolvida em pequenos grupos e depois, por meio de repetidas interações, estende-se à populações maiores.

${ }^{11}$ Para uma visão das várias posições relacionadas com a explicação de comportamentos altruístas de um ponto de vista evolutivo, veja-se também Hoffman (1981), Krebs (1982) e Bateson (2000).

${ }^{12}$ Sobre a relação entre seleção individual e de grupo veja-se Samuelson (1993). 
(também os do altruísmo) sobreviver e propagar-se (HAMiLTON, 1964). Neste caso o objetivo das escolhas tomadas pelos indivíduos, e dos seus eventuais sacrifícios, seria aquele de reproduzir os próprios genes (inclusive fitness) mais do que criar uma descendência direta. ${ }^{13}$

No entanto, na realidade também se observam casos nos quais o altruísmo não está exclusivamente relacionado com os membros da própria família. Alguns cientistas evolucionistas defendem que a validade do princípio da kin selection não requer necessariamente parentesco entre os indivíduos (veja-se por exemplo ALEXANDER, 1977 e HOFFMAN, 1981). É suficiente que os sujeitos acreditem ser parentes mesmo se na realidade não o forem. ${ }^{14}$ Esta idéia centrada no conceito de altruísmo recíproco permite alargar a aplicação do princípio da kin selection, propondo um princípio mais amplo de troca (adiada) de favores (cf. WILliAms, 1966 e TRIVERs, 1971). ${ }^{15}$ A desvantagem que resulta hoje de um gesto altruísta é recompensada pelo benefício futuro vindo do comportamento altruísta dos outros.

Se a troca de benefícios não é imediata, existe o risco de não se ter retribuído um favor. Para que o processo em discussão funcione, devem existir mecanismos capazes de eliminar quem não coopera, ou seja, quem não retribui o altruísmo. Tais mecanismos parecem de fato existir e Cosmides e Tooby(1992) chegam a analisar casos de troca recíproca de presentes com o modelo do tit for tat. Estes mesmos autores (p. 180) relatam evidência experimental em favor da hipótese que os indivíduos tenham desenvolvido mecanismos cognitivos para separar comportamentos egoístas e por conseguinte de repreender os mesmos ou excluir os indivíduos egoístas do grupo. ${ }^{16}$

${ }^{13}$ Esta explicação pode ser fundada na hipótese de gene egoísta introduzida por Dawkins (1976). Os genes seriam egoístas e interessados em sobreviver e reproduzirse, se necessário à desvantagem do próprio organismo que conforma.

${ }^{14}$ Numa fase primordial, quando as características do homo sapiens estavam em desenvolvimento, era provavelmente possível deduzir o parentesco entre indivíduos quase exclusivamente com base na sua participação em um mesmo grupo e por isso ao grau de semelhança. A tendência para ajudar as pessoas similares poderia tornar-se por isso natural, e independente do real parentesco biológico. De fato, "pesquisas em psicologia têm mostrado que somos propensos a ajudar pessoas que se parecem conosco, que são familiares, e que vivem próximas - características que esperaríamos serem associadas ao grau de parentesco entre indivíduos" (KREBS, 1982, p. 453).

${ }^{15}$ Para alguns autores a kin selection e o altruísmo recíproco têm na realidade a mesma explicação.

${ }^{16}$ Nas experiências conduzidas a este respeito, os sujeitos deveriam descobrir a violação de uma regra condicional (WASON, 1966). Em certos casos, ao se isolar a violação da regra percebeu-se um comportamento não cooperativo numa troca social. Os resultados sugerem que as pessoas não têm uma capacidade geral de isolar violações de 
Estes estudos parecem esvaziar a tradicional hipótese econômica de egoísmo puro, propondo um indivíduo com características diversas. O altruísmo (mesmo impuro) seria então uma tendência inata e transmitida em nível genético. Será então possível substituir o agente representativo egoísta pelo agente altruísta?

Provavelmente não, pelo menos enquanto a mesma evidência empírica que fragiliza a idéia de agente representativo egoísta também fragilizar a simples hipótese oposta.

Para Witt (1985) a hereditariedade genética pode explicar bem certas formas de altruísmo, como a kin selection, mas não pode plenamente explicar o altruísmo recíproco - provavelmente a forma mais importante). A extraordinária evolução do cerébro humano e a reduzida pressão da seleção natural na idade moderna limitaria, além disso, a força das pressões biológicas e dos comportamentos fixados geneticamente. Assumiria, pelo contrário, uma maior relevância a capacidade de aprender. O altruísmo seria assim explicado sobre a base da hereditariedade cultural e da experiência pessoal.

Também Kourad Lorenz (1963, p. 83) parece opôr-se a uma visão muito simplística, observando que:

à medida que uma espécie animal se desenvolve, o aprendizado se torna mais importante, enquanto o comportamento nato, mesmo não perdendo importância, é reduzido a elementos mais simples, mesmo que não sejam menos numerosos. Essa tendência faz mais significativo o papel do animal experiente e hábil. Pode-se dizer que uma nova função é desenvolvida: a de transmissão social do conhecimento individual através de tradições. É também possível perceber a mesma coisa de uma perspectiva oposta. A vida social exerce pressão para que se desenvolva melhor a habilidade individual de assimilar (tradições e conhecimento do ambiente social), posto que tais habilidades são úteis para ambos, indivíduo e sociedade.

Num certo ponto do desenvolvimento, a evolução poderia privilegiar os indivíduos que sabem aprender e conformar-se com as normas culturais. Aprendizagem e normas culturais podem, por isso, desempenhar um papel central, sem eliminar a relevância dos aspectos biológicos inatos.

regras condicionais (pelo menos em raciocínios abstratos). Elas, porém, parecem ter desenvolvido gradualmente instrumentos para descobrir violações de regras condicionais que subentendem comportamentos de free-rider. 


\section{ALTRUÍSMO COMO PRODUTO DE NORMAS CULTURAIS, RACIONALIDADE LIMITADA E PROCESSOS DE APRENDIZADO}

Continuando numa ótica de análise evolucionista, será então possível explicar o altruísmo fazendo recurso à idéia de seleção cultural das normas em alternativa, ou sobreposição, à seleção genética. As normas culturais podem ser vistas como instrumentos que garantirão comportamentos altruístas na interação social, mesmo se os indivíduos fossem programados para serem egoístas. ${ }^{17}$

Então, mesmo se o motor da economia é o interesse pessoal, os indivíduos têm uma tendência a agir segundo as regras da sociedade onde vivem (HAYEK, 1967). Num nível social, as regras são selecionadas com base na eficiência para o grupo. Na medida em que uma certa tendência à cooperação é útil a um grupo social é possível que se torne uma norma. ${ }^{18} \mathrm{O}$ estudioso austríaco propõe uma idéia parecida àquela vista na literatura biológica que se refere à hipótese do group selection. Neste caso, porém, a seleção se dá em um nível cultural e não genético.

Para Hayek (1967), num nível individual, as regras de conduta podem ser inatas ou adquiridas. Os dois tipos de regras podem interagir. Num outro trabalho o economista autríaco centra sua atenção exclusivamente nas normas evoluídas culturalmente (cf. HAYEK, 1978) e adquiridas dos indivíduos via imitação (HAYEK, 1963). As características genéticas determinariam, de um outro modo, uma tendência natural a "perceber regras (ou regularidades ou esquemas) nas ações dos outros" (HAYEK, 1963, p. 109). Estes mecanismos de imitação permitiriam aos indivíduos adquirir os modelos mentais do grupo ao qual pertencem e então garantir a possibilidade de comunicação com os outros e de repartir com eles uma hierarquia de valores.

A imitação tem então um papel central neste modelo, que é fundado na idéia de que a racionalidade individual seja fortemente limitada e o conhecimento individual heterogêneo. Por este motivo os agentes desen-

17 "Se somos altruistas por natureza, teríamos que desenvolver prescrições legais, sociais, morais, e religiosas para garantir que as pessoas ajudassem umas às outras?" (KREBS, 1982, p. 447).

18 “As propriedades individuais importantes para a existência e a preservação do grupo, e de consequência também para a existência e a preservação dos mesmos indivíduos, tomaram forma na seleção daqueles provenientes dos indivíduos que vivem em grupos os quais em cada estágio da evolução mostraram uma tendência a agir com base em regras tais que deixam o grupo mais eficiente" (HAYEK, 1967, p. 153). 
volvem uma "preferência pelos tipos de ações cujas conseqüências sejam previsíveis e medo nos confrontos cujas conseqüências sejam imprevisíveis" (HAYEK, 1967, p. 164).

Uma instituição em particular, o mercado, é relevante ao consentir que indivíduos egoístas e que não se conhecem colaborem numa união de bem-estar recíproco. ${ }^{19}$ Em algumas situações o mercado pode, porém, não ser capaz de funcionar adequadamente sem o suporte de outras instituições, dentre as quais, por exemplo, a reputação (HAYEK, 1949, p. 97).

A importância da reputação é evidenciada também por Tullock (1985, 1999). ${ }^{20}$ Tullock se une explicitamente a Adam Smith e tenta formalizar, num contexto de dilema do prisioneiro repetido, o modelo de mercado e uma "disciplina de negociações constantes." Na vida cotidiana são muitas as situações de trocas nas quais os indivíduos teriam interesse em não se comportar de forma socialmente aceita, ou ser incorretos com os outros. Eles, porém, não o fazem, pois pensam ser vantajoso criar fama de pessoa correta. A matriz do dilema do prisioneiro deveria então apresentar uma terceira escolha: não jogar com um certo parceiro que não desenvolve sua reputação (cf. também SEN (1984).

Aspectos biológicos e culturais, limitações de racionalidade e aprendizado são as bases da visão de Simon (1983, 1993), que apresenta muitos pontos em comum com a visão de Hayek. As pessoas teriam uma tendência a depender de conselhos, sugestões e informações obtidos por meio de canais sociais e a conformar-se a comportamentos socialmente aprovados. Não havendo um conhecimento perfeito em função da racionalidade limitada, é conveniente para as pessoas seguir as normas e as indicações provenientes do próprio ambiente. Seguindo estas indicações, as pessoas se encontram numa situação de sempre obedecer a algumas regras que na realidade são, para eles, desvantajosas. Complexamente, isso é útil à medida que os custos que se impõem sejam menores do que os ganhos. De acordo com Simon (1993, p. 157):

Enquanto o custo do altruísmo for menor que o ganho obtido com outras opções, indivíduos dóceis continuarão sendo melhor adaptados que os não dóceis. Se o custo individual de adaptação é menor do que o valor das ações altruísticas em aumentar a adaptação media dos membros da sociedade, então a sociedade vai se beneficiar do altruísmo na competição com outras sociedades.

Shapiro (1983).

${ }^{19}$ Sobre este aspecto são célebres também as posições de Adam Smith.

${ }^{20}$ Sobre o papel da reputação nos processos econômicos, veja também 
O próprio Simon (1991, 1993), e também Witt (1998), por exemplo, utilizam tais idéias como base para teorias da firma em que se destaca a lealdade nas relações, e não o oportunismo dos indivíduos. ${ }^{21}$

\section{ALTRUÍSMO COMO RESULTADO DE INCERTEZA OU ERROS}

A ligação entre incerteza e o surgimento de normas e comportamentos sociais é analisado por Scheling $(1958,1969)$, utilizando a idéia de pontos focais. ${ }^{22}$ Arrow (1986), por sua vez, o faz por meio de uma análise de jogos com equilíbrios múltiplos. Nos problemas de coordenação, os sujeitos optam, em geral, incluindo situações de possível conflito, por soluções de pontos focais, cuja natureza é prevalentemente cultural. A escolha dos pontos focais é aquela que garante a menor incerteza sobre o resultado. Como observa Ochs (1995, p. 195): “em jogos com equilíbrios múltiplos a racionalidade exigida é...um fenômeno social, e não uma característica dos indivíduos." Neste caso então, a incerteza traz resultados semelhantes aos trazidos pela idéia de racionalidade limitada.

Também Shafir e Tversky (1992) explicam alguns comportamentos cooperativos utilizando a incerteza. Eles confrontam as taxas de cooperação em um experimento do tipo dilema do prisioneiro com as taxas de cooperação em um experimento análogo no qual os sujeitos conhecem de antemão a escolha feita pelo rival. Neste caso, as taxas de cooperação resultantes são mais baixas do que nos jogos tradicionais que evidenciam uma tendência, mesmo não perfeita, ao altruísmo. Os indivíduos cooperam em medida menor também quando o parceiro escolhe colaborar. Em face a tais resultados, os dois autores sugerem que a cooperação observada no dilema do prisioneiro possa ser, na realidade, devida à dificuldade de avaliar as conseqüências da própria escolha frente à incerteza a cerca do comportamento do parceiro. No jogo modificado, esta incerteza desaparece e, em conseqüência, se reduz também a tendência ao altruísmo. ${ }^{23}$

${ }^{21}$ Em outro trabalho (NOVARESE, 2001) procedo à análise de tal literatura.

${ }^{22}$ No caso célebre, duas pessoas, não comunicadas, devem dividir uma cifra de 100 , e decidem por uma divisião igualitária.

${ }^{23}$ Cf. KREPS et al. (1982). A incerteza sobre o comportamento dos outros tem efeitos semelhantes em outros experimentos. Cf. SCHOTTER-WEIGEKT; WILSON (1994) onde os sujeitos declaram não haver feito a melhor escolha teórica por desconfiança na racionalidade dos outros participantes. 
Nos experimentos a incerteza pode assumir uma outra forma, ligada à limitada compreensão do jogo (ANDREONI, 1995). O aprendizado, aqui em contraste às considerações de Hayek ou de Simon, pode então comportar comportamentos menos ligados à cooperação e mais voltados ao interesse próprio. Quando os experimentos prevêem um certo número de rodadas, com freqüência as taxas de cooperação tendem a declinar. ${ }^{24}$ Diante dos resultados, Andreoni (1995) pôde concluir que cerca de metade da cooperação observada se dava devido à confusão. A outra metade, porém, podia ser explicada pela tendência ao altruísmo.

O declínio das taxas de cooperação pode ser interpretado também com base em outras hipóteses. $\mathrm{O}$ altruísmo inicial poderia ser ditado por motivos estratégicos (cria-se a fama de cooperador para poder enganar mais facilmente os demais jogadores nos turnos finais). Se assim fosse, o altruísmo seria mais instrumental.

Como observado por Andreoni (1995) e Ostrom (2000) - cf. também Rabin (1993) - a redução da taxa de cooperação pode, porém, depender da percepção (verdadeira ou não) de que os outros não estão colaborando, deflagrando um desejo de revanche. Esta explicação faz referência, direta ou indiretamente, à explicação do altruísmo por meio de emoções. ${ }^{25}$

\section{ALTRUÍSMO COMO PRODUTO DAS EMOÇÕES}

No âmbito da psicologia, o altruísmo está freqüentemente relacionado a emoções como empatia e a simpatia, consideradas mediadoras de diversos comportamentos morais (EISEMBERG; MILLER, 1987). Em termos gerais, a empatia é uma resposta emotiva provocada por um estado de espírito ou de uma condição vivida por outro indivíduo. Por exemplo, se observo uma pessoa que está em situação de perigo, a reação empática faz-me expe-

${ }^{24}$ BOONE et al. (1999) e RAIFFA (1982) têm resultados opostos: os sujeitos aprendem a cooperar no avançar do jogo.

${ }^{25} \mathrm{O}$ quanto o laboratório consegue limitar as influências sociais e culturais na base do altruísmo é uma questão importante. Os fatores que podem influenciar a escolha de ser mais ou menos altruístas são variados e não totalmente conhecidos, sendo difícil tê-los sob controle. Os resultados da economia experimental podem, por isso, ser um tanto distorcidos. Ainda mais, diversos experimentos sobre comportamento cooperativo podem ser envoltos por importantes aspectos de montagem do experimento. É comum que os sujeitos experimentais sejam estudantes de economia, tirando representatividade da amostra. Por exemplo, estudantes de economia parecem demonstrar uma tendência maior ao free-riding do que outros (cf. FRANK et al., 1993). 
rimentar estado de espírito semelhante ao de tal pessoa e poderei ser impelido a ajudá-la. Os vários trabalhos elaborados por Eisenberg e Miller (1987), Hoffman (1981) e Krebs (1982), evidenciam como a pesquisa no campo psicológico está destinada, acima de tudo, a determinar se a empatia e o altruísmo estão efetivamente interligados. A resposta é geralmente positiva.

A análise de Hoffman (1981) é dedicada a um tipo de comportamento altruísta muito particular, como a atitude de socorrer quem se encontre em situação de perigo. Num caso como este, a empatia parece ser um sentimento inato, presumivelmente universal (não relacionado portanto a dadas culturas) e justificável na base de uma hipótese de seleção natural.

Aronfreed (1970) observa como a empatia é adquirida por crianças, relacionando os próprios sentimentos de prazer ou dor a emoções correspondentes de outros por meio de um processo de condicionamento. Os sentimentos dos adultos estimulam as emoções correspondentes nas crianças, que apreendem como sendo agradáveis também os comportamentos que fazem os outros felizes. O comportamento social estaria assim ligado às emoções por dois processos de apreensão (cujo papel é assim novamente evidenciado) auto-reforçante.

Assim sendo, a empatia é um fator importante, mas não único. De fato, perante uma reação empática, não se obtém necessariamente um comportamento altruísta. Para Hoffman, por exemplo, a empatia simplesmente estimula o indivíduo a ajudar quem está em perigo, mas não o impele, necessariamente, a prestar-lhe socorro. A tendência para ajudar é contida pelo egoísmo (que resiste ainda que na presença de impulsos opostos). A decisão final é tomada com base numa espécie de cálculo custo-benefício. Uma tendência automática para a ajuda poderia de fato ser danosa, também no âmbito de grupo, para um processo evolutivo.

Lorenz (1963) evidencia, de forma pelo menos em parte análoga, como os comportamentos animais são determinados por uma combinação de estímulos diversos, por vezes também em contraste entre eles. De fato os instintos não são modelados com um objetivo único e particular. ${ }^{26}$ Estendendo tais observações pode-se, portanto, observar que as emoções podem agir em direções diversas, e não é correto pensar que tenham sido

${ }^{26}$ Este observa como o instinto para a caça, típica dos cães, não está exclusivamente relacionado com a busca de comida. Também um cão sem fome tem impulso para farejar e perseguir uma presa. Quando está esfomeado tais impulsos são ainda mais fortes. Cada movimento instintivo destinado a satisfazer a função de procurar comida não é ativado só pela fome, mas por uma série de impulsos, alguns entre eles autônomos (LORENZ, 1963, p. 130-135). 
selecionadas somente com o objetivo de "garantir um comportamento altruísta." Nem se pode pensar que as escolhas altruístas sejam o resultado de um único tipo de estímulo.

Dado que um gesto análogo pode ter motivações diversas é, além disso, possível verificar gestos altruístas diante de situações que não provoquem empatia.

A análise das emoções encontra-se também, se bem que de forma muito limitada, na literatura econômica. Como observado por Elster (1998) e por Hermalin e Isen (1999, p. 2): "referência a humor e outras emoções em economia é rara. Quando tal referência é feita, em geral serve para explicar algum tipo de comportamento que parece inconsistente com um auto-interesse restrito. Por exemplo, honestidade em situações onde desonestidade pareceria proporcionar recompensas maiores." O remorso conseqüente de um comportamento egoísta poderia, nesta perspectiva, ser dissuasivo nos confrontos de certas ações.

A ligação entre emoções e altruísmo é integrável num esquema de seleção natural. As emoções, poderiam ser o instrumento modelado pela evolução (transmitido geneticamente e portanto inato aos indivíduos) com o objetivo de possibilitar um comportamento altruísta. Desta forma também se podem racionalizar as emoções, transformando-as em parte de uma estratégia altruísta destinada a garantir equilíbrios mais eficientes. Tal raciocínio é proposto por Frank (1988), Romer (1999) e Rotemberg (1994), mas encontra resistência na linha seguida por Lorens (1963).

Rabin (1993) insere algumas noções psicológicas relativas ao altruísmo e ao comportamento em relação aos outros num contexto de teoria dos jogos. Também Brams (1997) introduz as emoções (em particular a frustração) num contexto de teoria dos jogos. Em determinadas situações, a expressão aparentemente irracional da própria frustração pode revelar-se uma escolha racional na medida em que permite tornar crível uma ameaça (que numa reação "racional" em que a frustração não fosse expressa não seria levada a sério). Além disso, os indivíduos só são geralmente generosos com quem se comporta da mesma forma, mas tendem a comportar-se incorretamente (ainda que com o risco de sofrer as conseqüências) com quem não foi correto. As experiências de Kaheneman, Knetsch, Thaler (1986, p. 105-108), Andreoni (1995), e Fehr e Gachter (2000) evidenciam o desejo de punir quem se comporta desonestamente.

Os equilíbrios deste modelo impõem um comportamento simétrico por parte dos indivíduos. Não é possível que, em equilíbrio, uma pessoa seja correta e outra não. São portanto excluídas estratégias de altruísmo puro (a estratégia do tit for tat parece ser de novo uma síntese válida). 
Considerações que estão na linha das de Rabin sobre o papel das emoções, em particular sobre o desejo de ser tratado honestamente, são propostas por Akerlof e Yellen numa análise do mercado de trabalho (AKERLOF, 1984, e AKERLOF; YELLEN, 1987, 1988). O rendimento e o esforço dispendidos por um trabalhador dependem da honestidade com a qual julga ter sido tratado pela empresa. As relações entre trabalhador e empresa podem ser modeladas como uma "troca de bens" na qual "a lealdade dos empregados é trocada por altos salários." ${ }^{27}$ As empresas podem portanto achar útil pagar um sálario superior ao de market clearing e não reduzir o salário no caso de recessão e em presença de desocupação (trata-se da teoria dos salários de eficiência proposta inicialmente por SHAPIRO; STIGLIZ, 1984). Também nestes modelos, um comportamento honesto pode portanto ser eficiente e é premiado quem o desempenha.

\section{CONCLUSÕES}

Os comportamentos altruístas observados empiricamente podem ser explicados com base em diversas motivações. Em certos casos o altruísmo pode ser, na realidade, somente aparente, mas motivado por impulsos egoístas. Todas as abordagens analisadas tendem geralmente a excluir o altruísmo puro - aquelas formas de comportamento que não trazem nenhuma vantagem, direta ou indireta, a quem as realiza ou à sua descendência. Formas moderadas de altruísmo podem se revelar racionais ou vantajosas. ${ }^{28}$

É precisamente por este motivo que tais formas de comportamento podem ser o resultado de processos de seleção cultural ou biológica. É possível pensar numa interação entre os dois tipos de evolução. De fato, é difícil excluir completamente uma das duas causas em vantagem exclusiva da outra. Por exemplo, os indivíduos poderiam ser geneticamente programados para aprender a interiorizar as normas que dentro de certos grupos sociais são consideradas não egoístas (cf. HOFFMAN, 1981, p. 128, e ostrom, 2000, p. 143). Tais normas poderiam, no entanto, diferir de cultura a cultura e variar no tempo.

${ }^{27}$ Note-se que neste modelo o maior esforço dos trabalhadores não é motivado pelo desejo de obter incentivos salariais, mas sim pela lealdade.

${ }^{28}$ Simon $(1983,1993)$ nota como se pode adotar duas definições de altruísmo, uma forte (sacrifício da própria capacidade de adaptação) e uma fraca (que é interpretável como interesse pessoal temperado). Esta última parece ser a única sustentável num processo de seleção natural, já que indiretamente vantajosa para quem a tem. 
É este mesmo o aspecto que faz com que a natureza (cultural ou genética) dos processos evolutivos em questão não seja indiferente. É claro que um comportamento imposto geneticamente deveria ter uma força e uma persuasão maiores. Deveria, além disso, ser comum a todos os indivíduos, independentemente da sua cultura de origem.

Uma hipótese parcialmente alternativa poderia atribuir ao altruísmo evoluído biologicamente e àquele evoluído culturalmetne diversos campos de ações. De fato existem diversas formas de comportamento altruístico. Em determinados casos o altruísmo pode ser um reflexo (quase automático), em outros não.

A comunidade pertencente a um grupo é um dos fatores que análises diversas indicaram (direta ou indiretamente) como fonte de prováveis comportamentos não egoísticos. $\mathrm{O}$ fato de pertencer a um mesmo ambiente social facilita a co-divisão das normas culturais e a individualização de pontos comuns. Torna, provavelmente, mais fácil a confiança necessária para as escolhas altruísticas, as quais devem ser, ao menos potencialmente, recíprocas. De maneira similar, seria importante distinguir entre troca pessoal e impessoal, como o fez Adam Smith.

Ainda nos aspectos culturais e biológicos, existem, porém, em jogo fatores individuais ligados à personalidade e à experiência de qualquer um. Boone et al. (1999) analisam experimentalmente a relação entre algumas características individuais e a tendência à cooperação. A conclusão é que "a personalidade do jogador importa."

Resta explicar os motivos pelos quais os sujeitos com algumas características pessoais análogas têm comportamentos heterogêneos em termos de altruísmo. É possível por exemplo que tais diferenças dependam dos variados estilos de aprendizados, atitudes de risco, confiança nos outros ou na própria capacidade de influenciar o comportamento dos outros (PRUITT; KIMMEL, 1977).

Motivações por comportamento não egoísta podem vir da esolha concebível do tipo ético (SEN, 1985). O altruísmo como escolha ética é motivado pela idéia "comportar-se assim é justo." Diferente é dizer "me comporto assim porque de um outro modo sinto culpa" ou ainda "me comporto assim porque sinto prazer," ou "me comporto assim porque é útil." Não se trata de questões puramente formais. Conhecendo-se as motivações é possível avaliar quando serão deflagrados os comportamentos altruísticos e que forma tomarão. Conhecer os gostos e as atitudes dos indivíduos é importante para a economia do bem-estar e das escolhas políticas.

A complexidade da matéria analisada neste trabalho e a sua relevância para a análise econômica pedem, em conclusão, maior aprofundamento. 
O tema é complexo e relevante. A análise empírica há de ser evidentemente um ponto fundamental deste projeto de pesquisa, afinal, como dizem Kahneman, Knetsch e Thaler (1986, p. 114): "as regras de honestidade e justiça não podem ser inferidas dos princípios econômicos tradicionais nem da intuição ou introspecção."

Parte do trabalho pode ser conduzido em colaboração com outras disciplinas. Existem, porém, evidentes aspectos que são de pertinência específica da economia, tais quais os envolvidos na compreensão de situações econômicas onde agem instituições e mediadores.

\title{
RESUMO
}

O artigo tem por objeto a análise da literatura (econômica e também psicológica e sociobiológica) que enfoca o altruísmo, entendido como negação de um comportamento puramente voltado ao próprio interesse. O comportamento egoísta geralmente tratado no âmbito dos tradicionais modelos econômicos é negado por meio de uma ampla série de observações empíricas e experimentais. Diferentes explicações têm avançado no sentido de justificar estes comportamentos. Uma idéia central é aquela de seleção cultural ou biológica que se conecta a vários temas: emoções, incerteza, racionalidade e processo cognitivo. O objetivo é fornecer ao leitor um survey das posições contemporâneas a respeito do confronto, e a possível integração, entre hipóteses de comportamentos egoísta e altruísta puros.

Palavras-chave: altruísmo, cultura, racionalidade, evolução.

\begin{abstract}
This article analyses the literature on altruism produced in economics (and also in psychology and socio-biology). Altruism is generally regarded as behaviour alternative to self-interest pursuit. Selfish behaviour, as assumed by traditional economic models, is contested by a vast series of empirical and experimental observations. As a result, different accounts have been produced to explain altruistic behaviour. The idea of cultural or biological selection plays a key role among them, involving elements as various as emotions, uncertainty, rationality and cognitive processes. The aim of the article is to provide a survey of the current standings on the issue of which assumption, the selfishness or the altruistic treat of human behavior, is the most
\end{abstract}


apposite to economic studies, and whether or not they can both stand together in the field.

Key-words: altruism, culture, rationality, evolution.

\section{REFERÊNCIAS}

AKERLOF, G. A. Gift Exchange and Efficiency-Wage Theory: Four Views. The American Economic Review, v. 74, Issue 2, Papers and Proceedings of the Ninety-Sixth Annual Meeting of the American Economic Association. May, 1984. p. 79-83.

; YELLEN, J. L. Fairness and Unemployment. The American Economic Review, v. 78, Issue 2, Papers and Proceedings of the One-Hundred Annual Meeting of the American Economic Association. p. 44-49. May 1988.

ALEXANDER, R. D. Natural Selection and the analysis of human sociality. In: GOULDEN, C. E. (Ed.). Changing scenes in natural sciences: 1776-1976. Philadelphia: Academy of Natural Sciences, 1977.

ANDREONI, J. Cooperation in Public-Goods Experiments: Kindness or Confusion? The American Economic Review, v. 85, Issue 4, p. 891-904. Sep. 1995.

; MILLER, J. H. Rational Cooperation in the Finitely Repeated Prisoner's Dilemma: Experimental Evidence. The Economic Journal, v. 103, Issue 418. p. 570-585. May 1993.

ARONFREED, J. The Socialization of altruistic and sympathetic behavior: Some theoretical and experimental analyses. In: MACAULEY, J.; BERKOWITZ, L. (Eds.). Altruism and helping behavior. New York: Academic Press, 1970. p. 103-126.

AXELROD, R. The Evolution of Cooperation. New York: Basic Books, 1984.

; HAMiLTON, W. D. The Evolution of Cooperation. Science, v. 211, 1981. p.1390-1396.

BECKER, G. S. Altruism, Egoism, and Genetic Fitness: Economics and Sociobiology. Journal of Economic Literature, v. 14, Issue 3. p. 817-826. Sep. 1976.

BERGSTROM, T. C.; STARK, O. How altruism can prevail in a Evolutionary Environment. The American Economic Review, v. 83, Issue 2. p. 149-155. May 1993.

BICCHIERI, C. Norms of Cooperation. Ethics, v. 100, Issue 4, p. 838-861. 1990.

; JEFFREY, R.; SKYRMS, B. The Dynamics of Norms. Cambridge: Cambridge University Press, 1997.

BOONE, C.; DE BRABANDER, B.; VAN WITTELOOSTUIJN, A. The Impact of personality on behavior in five Prisoner's Dilemma games. Journal of Economic Psychology, 20, p. 343-377. 1999.

COSMIDES, L.; TOOBY, J. Cognitive Adaptations for Social Exchange. In: BARKOW, J. H.; COSMIDES, L.; TOOBY, J. (Eds.). The Adapted Mind. New York: Oxford University Press, 1992. p. 163-228.

CROSON, R. T. A. Partners and strangers revisite. Economics Letters, 53, 1996. p. $25-$ 32 . 
DAWKINS, R. The Selfish Gene. New York: Oxford University Press, 1976.

EISENBERG, N.; MILLER, P. A. Empathy, Sympathy, and altruism: Empirical and Conceptual Links. In: EISENBERG, N.; STRAYER, J. (Eds.). Empathy and its Development. Cambridge: Cambridge University Press, 1987. p. 292-316.

ELSTER, J. Emotions and Economic Theory. Journal of Economic Literature, 36 (1), p. 47-74. March 1998.

FEHR, E.; GACHTER, S. Fairness and Retaliation: The Economics of Reciprocity, Collective Action and the Evolution of Social Norms. Journal of Economic Perspectives, n. 3, p. 159-181. Summer 2000.

FLOOD, M. M. Some experimental Games. Research Memorandum, n. 789, RAND Corporation, 1952.

Some experimental Games. Management Science, n. 5, p. 5-26. 1958.

FRANK, R. Passions within Reason. New York: Norton, 1988.

HAMILTON, W. D. The genetical evolution of social behaviour. Parts I, II. Journal of Theoretical Biology, 7, p. 1-52. 1964.

HAYEK, F. The Meaning of Competition. In: HAYEK, F.;ROUTLEDGE, G.; KEGAN, Paul. Individualism and Economic Order. London, 1949.

Rules, Perception and Intelligibility. Proceedings of the British Academy, XLVIII, 1963. p. 321-344.

Notes on the Evolution of Systems of Rules of Conduct. Studies in Philosophy, Politics, and Economics, Chicago, The University of Chicago Press, 1967.

. The Errors of Constructivism. In: HAYEK, F. New Studies in Philosophy, Politics, Economics and the History of Ideas. Chicago:The University of Chicago Press, 1978.

HIRSHLEIFER, J. Competition, Cooperation, and Conflict in Economics and Biology. The American Economic Review, v. 68, Issue 2, p. 238-243. May 1978.

HOFFMAN, M. L. Is altruism Part of Human Nature? Journal of Personality and Social Psychology, 40(1), p. 121-137. 1981.

KAHNEMAN, D.; KNETSCH, J.; THALER, R. Fairness as a Constraint on Profit Seeking: Entitlements in the Market. The American Economic Review, v. 76, Issue 4, p. 728-741. Sep. 1986.

KREBS, D. Psychological Approaches to Altruism: An Evaluation. Ethics, 92 (3), p. 447-158. April 1982.

KREPS, D. et al. Rational cooperation in the Repeated Prisoner's Dilemma. Journal of Economic Theory, 27, p. 245-252. 1982.

LEDYARD, J. O. Public Goods: A Survey of Experimental Research. In: KAGEL, J. H.; ROTH, A. E. (Eds.). The Handbook of Experimental Economics, Princeton: Princeton University Press, 1995. p. 111-193.

LORENZ, K. Das sogenannte Böse: Zur Naturgeschichte der Aggression, Dr. G. Borotha Schoeler, Verlag, Wien, 1963.

NOVARESE, M. Lealtà, organizzazioni e innovazione nella teoria eterodossa dell'impresa. Paper presented to the VI Convegno Aispe, Associazione Italiana per la 
Storia del pensiero economico, Università degli studi di Lecce, May 2001. p. 24-26.

NOVARESE, M.; RIZZELLO, S. Origin and Recent Development of Experimental Economics. Storia del pensiero Economico, 37, p. 201-234. 1999.

OCHS, J. Coordination Problems. In: KAGEL, J. H.; ROTH, A. E. (Eds.). The Handbook of Experimental Economics, Princeton, Princeton University Press, 1995. p. 195-251.

OSTROM, E. Collective Action and the Evolution of Social Norms. Journal of Economic Perspectives, n. 3, p. 137-158. Summer 2000.

RABIN, M. Incorporating Fairness into Game Theory and Economics. The American Economic Review, v. 83, Issue 5, p. 1281-1302. Dec. 1993.

RAIFFA, H. The art and science of negotiation. Cambridge: Harward University Press, MA, 1982.

RIZZELLO, S. The Economics of the Mind. Edward Elgar, Aldershot, 1999.

SACCO, P. L.; ZAMAGNI, S. Un'approccio dinamico evolutivo all'altruismo. Rivista Internazionale di Scienze Sociali, 4-6, CII:2, p. 223-262. 1994.

SCHELlinG, T. C. The Strategy of Conflict. Cambridge: Harvard University Press, 1960 .

SELTEN, R. (Ed.). Game Equilibrium Models. Volume I. Evolution and Game Dynamics. New York, Berlin, London and Tokyo: Springer, 1991.

SEN, A. Resources, Values and Development. Oxford: Blackwell; Cambridge: Harward University Press, 1984.

Goals, Committment, and Identity. Journal of Law, Economics, and Organizations, 1 (2), p. 341-355. Fall 1985.

SHAFIR, E.; TVERSKY, A. Thinking through uncertainty: Nonconsequential reasoning and choiche. Cognitive Psychology, 24, p. 449-474. 1992.

SHAPIRO, C. Premiums for High Quality Products as Returns to Reputation. Quarterly Journal of Economics, p. 657-679. Nov. 1983.

; STIGLIZ, J. E. Equilibrium Unemployment as a Worker Discipline Device. The American Economic Review, v. 74, Issue 3, Jun. 1984.

SIMON, H. A. Reason in Human Affairs. Stanford, CA: Stanford University Press, 1983.

Organizations and Markets. Journal of Economics Perspective, v. 5, n. 2, p. 2544. Spring, 1991.

Altruism and Economics. The American Economic Review, v. 83, Issue 2, p. 156-161. May 1993.

SKYRMS, B. The Evolution of Social Contract. Cambridge: Cambridge University Press, 1996.

SMITH, A. The Theory of Moral Sentiments. London: A. Millar; Edinburgh: A. Kincaid / J. Bell, 1759.

. An Inquiry into the Nature and Causes of the Wealth of Nations. London: W. Strahan / T. Cadell, 1776.

SMITH, V. L. The Two Faces of Adam Smith. Southern Economic Association. 
Distinguished Guest Lecture. Atalanta, Nov. 21, 1997.

TRIVERS, L. The evolution of reciprocal altruism. Quarterly Review of Biology, 46, p. 35-57, 1971.

TULLOCK, G. Adam Smith and the Prisoners' Dilemma. The Quarterly Journal of Economics, v. 100, Issue Supplement, p. 1073-1081, 1985.

Non-prisoner's dilemma. Journal of Economic Behavior \& Organization, v. 39, p. 455-458, 1999.

WASON, P. Reasoning. In: FOSS, B. M. (Ed.). New horizons in psychology. Penguin, Harmonsdworth, 1966.

WILliamS, G. C. Adaptation and Natural Selection: A Critique of some current evolutionary thought. Princeton: Princeton University Press, 1966.

WILSON, E. O. Sociobiology. Cambridge: Harward University Press, MA, 1975.

WITT, U. Imagination and leadership - The neglected dimension of an evolutionary theory of the firm. Journal of Economic Behavior \& Organization, v. 35, p. 161-177, 1998.

Economic Behavior and Biological Evolution: Some Remarks on the Sociobiology Debate. Journal of Institutional and Theoretical Economics, 141, 1985. p. 365-389.

YOUNG, H. P.; FOSTER, D. Cooperation in the Short and in the Long Run. Games and Economic Behavior, 3, p. 145-156, 1991. 